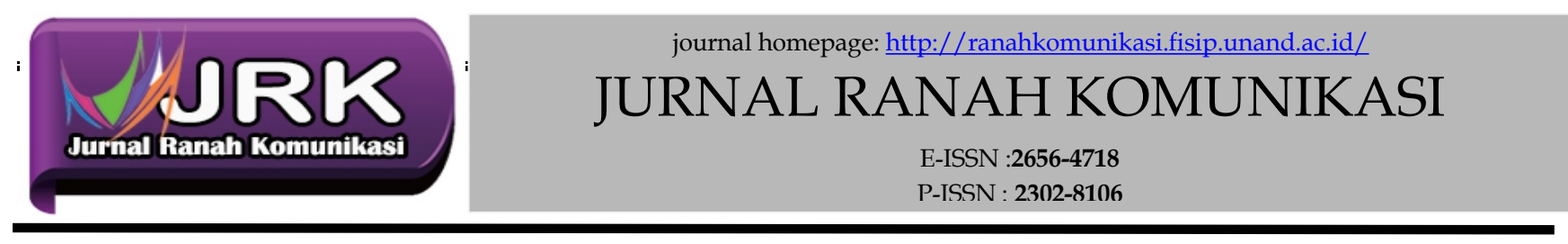

\title{
Transformasi Media Youtube dan Televisi (Analisis Fungsi dan Konsumsi Media Youtube dan Televisi di Kota Padang)
}

\author{
Alna Hanana ${ }^{1)}$, Annisa Anindya ${ }^{2),}$ Novi Elian ${ }^{3)}$ \\ 1)Ilmu Komunikasi, FISIP Universitas Andalas, email: alna@soc.unand.ac.id \\ 2) Ilmu Komunikasi, FISIP Universitas Andalas, email: annisaanindya@soc.unand.ac.id \\ 3) Ilmu Komunikasi, FISIP Universitas Andalas, email: novielian88@gmail.com
}

\section{ARTICLE INFORMATION}

KEYWORDS:

media consumption, function transformation, television, youtube

CORRESPONDENCE

Phone: +62 821-7022-5066

E-mail: alna@soc.unand.ac.id

\begin{abstract}
A B $\mathbf{S}$ T $\mathbf{R}$ A C $\mathbf{T}$
If we talk about television as mass media, what is meant by watching $T V$ is watching programs that are broadcast by television stations. It's just that, seeing the arrival and influence of new media technology at this time, making many functions of the mass media that began to be seized by new media. This research was conducted to see how the process of transformation of functions and consumption of television and Youtube media is carried out by the people of Padang City. In order to examine the changes in this communication media, of course data is needed on how the actual process takes place in the field. To examine the problem, this study uses MediaMorphosis Theory. The study was designed using a quantitative and qualitative mixed approach that was shaded by a post-positiveist paradigm. The quantitative approach is carried out through an explanatory research survey research design to find out the situation or condition that occurs and the factors influencing it. While the qualitative approach is used to explain the variables studied in more detail. The results revealed that the majority of respondents are more concerned with the content presented than the media platform used. The platform only functions as a tool that makes it easy for them to access the content they want, without them really caring about the conceptual differences from the available media choices.
\end{abstract}

\section{INTRODUCTION}

Selama puluhan tahun, televisi sebagai salah satu media massa, telah menjadi media hiburan dan informasi yang paling digemari karena keistimewaannya dalam reproduksi kenyataan dalam bentuk audio visual. Karena kelebihan televisi yang menampilkan informasi secara menarik inilah yang memudahkan khalayak untuk menerima informasi secara cepat dan mudah (Yulianti, 2013). TVRI (Televisi Republik Indonesia) adalah televisi nasional pertama di Indonesia yang memulai kegiatan penyiaran di Indonesia bertepatan dengan dilangsungkannya pembukaan pesta olahraga se-Asia IV atau Asean Games pada tanggal 24 Agustus 1962. TVRI menyiarkan siaran selama rata-rata satu jam sehari selama tahun 1962-1963. TVRI mendapat saingan dengan kemunculan stasiun televisi lain pada tahun 1989, yaitu dengan adanya RCTI (Rajawali Citra Televisi Indonesia) yang bersifat komersil. Kemudian secara berturutturut bermunculan stasiun televisi komersil lainnya yaitu SCTV (Surya Citra Televisi), TPI (Televisi Pendidikan Indonesia) dan ANTV (Andalas Televisi) (Fajri, 2015).

Jika kita berbicara mengenai televisi sebagai media massa, yang dimaksud dengan menonton TV adalah menonton programprogram yang ditayangkan oleh stasiun televisi. 
Televisi sebagai sebuah alat yang berbentuk persegi tersebut tidak bisa dipisahkan dengan tayangan acara dan program yang ditayangkannya. Program siaran sendiri dapat didefinisikan sebagai suatu bagian atau segmen dari isi siaran televisi ataupun radio secara keseluruhan. Segala hal yang di tampilkan stasiun penyiaran untuk memenuhi kebutuhan audiensinya itulah yang disebut dengan program (Morissan, 2008).

Hanya saja, melihat kedatangan dan pengaruh teknologi media baru saat ini, membuat banyak fungsi-fungsi dari media massa yang mulai tumpeng tindih dengan media baru. Salah satu contohnya adalah dengan adanya teknologi telepon pintar (smartphone) sebagai perkembangan dari telepon selular yang memiliki sarana untuk mengakses internet. Harganya smartphone inipun jauh lebih murah daripada PC atau laptop sehingga bisa berkembang dengan sangat pesat dan dengan cepat pula digemari oleh banyak orang. Salah satu fitur utama smartphone adalah kemudahan dalam mengakses media sosial.

Media sosial saat ini telah menjadi kebutuhan banyak orang, bahkan informasi yang berasal dari media online kebanyakan diakses oleh khalayak melalui link di media sosial. Sosial media adalah sebuah media online yang memungkinkan manusia untuk saling berinteraksi tanpa dibatasi ruang dan waktu, dan digunakan masyarakat untuk bersosialisasi satu sama lain (Gusnita \& Alviani, 2018). Pola penggunaan media massa pun dipengaruhi oleh makin besarnya pengguna internet yang sekaligus pengguna media sosial ini.

Khalayak mempunyai banyak pilihan media sosial baru yang ada di dalam internet dan bisa mereka akses kapan saja dimana saja dalam genggaman mereka. Saat ini, masyarakat bebas mengkonsumsi beragam konten, program bahkan film dan serial tanpa harus menyalakan televisi. Salah satu situs yang menyediakan segala fasilitas untuk menonton tayangan video ini adalah situs Youtube (Akbar, 2018; Mangole et al., 2017). Sebagaimana program acara televisi, Youtube juga mempunyai ragam jenis program tontonan, diantaranya berupa konten-konten: ulasan/review, tutorial, vlog, permainan, dan lainnya. Selain konten yang memang diciptakan oleh para pembuat konten (content creator), Youtube juga berisikan video-video yang disadur dari tayangan televisi, berbagai film, dan sebagainya.

Hal tersebut menunjukkan bahwa fungsi informasi dan hiburan dari media massa mulai direbut oleh media sosial ini, terutama fungsi televisi yang perlahan diambil alih oleh Youtube. Karenanya sudah selayaknya dengan kesamaan dan alih fungsi yang timbul, mediamedia baru seperti Youtube pun bisa kita sebut sebagai media penyiaran. Penyiaran merupakan kegiatan penyelenggaraan siaran yang ditransmisikan dalam bentuk sinyal suara atau gambar, baik melalui udara maupun melalui kabel dan atau serat optik dalam bentuk audio, suara atau visual gambar, di mana nantinya diterima oleh masyarakat melalui pesawat penerima di rumah-rumah (Sulvinajayanti, 2018).

Menariknya, ternyata saat ini bukan hanya media sosial yang mengambil alih fungsi media massa. Sebaliknya, media massa terutama televisi bertransformasi sedemikian rupa untuk bertahan dan tetap dikonsumsi. Salah satunya bisa kita lihat dari bukan hanya tayangan dan program televisi bisa diakses melalui Youtube, tetapi konten Youtube pun bisa kita tonton dari televisi. Hal ini menjadi memungkinkan dengan teknologi televisi pintar (smart tv) yang dimiliki oleh perangkat televisi saat ini. Televisi pun pada akhirnya mengadopsi teknologi internet sebagai kesatuan dalam perangkatnya agar tetap bisa bertahan dan menyesuaikan diri.

Televisi tidak lagi bisa kita lihat sebagai sebuah kesatuan antara perangkat dan 
tayangan. Kata televisi kini lebih cocok disebut mengacu pada perangkat sebagaimana kita menyebut handphone. Konten dan tayangan yang kita akses dari perangkat tersebut tidak lagi terbatas pada program yang dibuat oleh stasiun televisi melainkan juga dari situs dan aplikasi lain. Hal inilah yang dimaksud dengan transformasi fungsi antara media televisi dan Youtube, di mana kita bisa mengakses tayangan/konten televisi melalui Youtube, dan sebaliknya, kita bisa mengkonsumsi konten Youtube melalui televisi. Maka berdasarkan pemaparan tersebut maka penelitian ini dilaksanakan untuk melihat proses transformasi fungsi media yang terjadi, terutama pada masyarakat Kota Padang.

\section{METHOD}

Penelitian ini merupakan tahapan penelitian lanjutan dari survey yang sebelumnya telah dilakukan mengenai Intensitas Konsumsi Media Youtube dan Televisi pada Khalayak Kota Padang. Penelitian ini menggunakan metode deskriptif kualitatif dengan pendekatan studi kasus. Pendekatan kualitatif dalam penelitian ini digunakan untuk menjelaskan varaiabel yang diteliti secara lebih rinci.

Informan penelitian didapat dengan teknik purposive sampling, yaitu individu yang memenuhi kriteria sebagai berikut: (1) Menggunakan Youtube untuk mengakses Konten Youtube. (2) Menggunakan Youtube untuk mengakses Konten Non-Youtube (3) Menggunakan Televisi untuk menonton Program Stasiun TV. (4) Menggunakan Televisi untuk menonton Program Non-Stasiun TV.

Adapun informan penelitian dijelaskan pada tabel berikut:

Tabel 1. Informan Penelitian

\begin{tabular}{|c|c|c|c|c|}
\hline Deskripsi & Inisial & Usia & Pekerjaan & Pendidikan Terakhir \\
\hline Informan I & NR & 59 tahun & Pensiunan & Sarjana \\
\hline Informan II & ERR & 39 tahun & Dosen & Doktor \\
\hline Informan III & SR & 29 tahun & Pegawai & Sarjana \\
\hline Informan IV & RR & 22 tahun & Pegawai & Sarjana \\
\hline Informan V & YAF & 18 tahun & Mahasiswa & SMA \\
\hline Informan VI & NA & 12 tahun & Pelajar & SD \\
\hline
\end{tabular}

Proses pengumpulan data yang dilaksanakan di dalam penelitian ini menggunakan beberapa cara, diantaranya:

1. Wawancara (interview), di mana peneliti melakukan tanya jawab secara langsung dengan informan penelitian untuk mengumpulkan data dan informasi yang diperlukan

2. Pengamatan (observation), di mana peneliti mempelajari dan mencatat langsung fenomena ataupun detail kejadian yang terjadi di lokasi penelitian. Fenomena dan kejadian yang diamati berkaitan dengan pola konsumsi informan atas media terutama youtube dan televisi.
3. Dokumentasi (documentation), di mana peneliti mengumpulkan data dengan cara penelusuran dan pencatatan data, dokumen, arsip, maupun referensi yang relevan dari sumber ataupun instansi yang berkaitan dengan penelitian.

Uji keabsahan atau yang dikenal dengan analisis triangulasi dilakukan bertujuan untuk menganalisis jawaban subjek dengan meneliti kebenarannya melalui data empiris (sumber data lainnya) yang tersedia. Dalam penelitian ini jawaban informan di cross-check dengan dokumen dan sumber lain yang relevan (Kriyantono, 2009). Teknik keabsahan data perlu dilakukan agar data yang diperoleh lebih konsisten, tuntas, dan pasti. 
Pengolahan data pada penelitian ini memakai teknik analisis data Miles dan Huberman atau yang juga disebut teknik analisis interaktif (Sugiyono, 2009). Teknik analisis ini terdiri dari tiga komponen, yaitu Reduksi Data (Data Reduction), Penyajian Data (Data Display) dan Penarikan serta Pengujian Kesimpulan (Drawing and Verifying Conclussions).

Data hasil wawancara terlebih dahulu dibuatkan transkripnya, setelah itu direduksi sesuai kebutuhan penelitian. Setelah informasi disusun berdasarkan benang merah pembahasan, data disajikan dengan narasi dan dukungan hasil penelitian yang diperoleh. Selanjutnya setelah semua data disajikan dan dikaitkan dengan konsep dan teori yang digunakan, peneliti menarik kesimpulan berdasarkan rumusan masalah yang ditetapkan.

\section{RESULTS AND DISCUSSION}

\section{Hasil Penelitian}

Perubahan teknologi membuat munculnya banyak pilihan bagi khalayak untuk bebas mengkonsumsi beragam program dan konten. Sebagaimana penelitian ini melihat empat poin perubahan transformasi fungsi antara media Televisi dan Youtube, maka khalayak yang dimaksud dibagi sebagai berikut:

1. Menggunakan Youtube untuk mengakses Konten Youtube

2. Menggunakan Youtube untuk mengakses Konten Non-Youtube

3. Menggunakan Televisi untuk menonton Program Stasiun TV

4. Menggunakan Televisi untuk menonton Program Non-Stasiun TV

\section{Penggunaan Youtube untuk mengakses Konten Youtube}

Hasil penelitian, baik dari survei maupun wawancara khalayak yang dilakukan, menunjukkan bahwa setiap pengguna Youtube pasti menggunakan aplikasi ini untuk mengakses konten-konten yang memang dibuat oleh content creator (atau biasa juga disebut sebagai youtuber) yang memang khusus dibuat dan diupload untuk channel Youtube. 100 orang dari responden dan juga 5 orang informan yang diteliti memberikan jawaban yang sama, bahkan mereka mengakses Youtube untuk menikmati konten ini setiap hari. Adapun seperti yang disampaikan oleh informan Televisi untuk menonton Program Non-Stasiun IV, RR, bahwa aksesnya:

"Ya adalah satu sampai dua jam sehari, pulang kerja. Biasanya nonton food vlogger, beauty vlogger. Atau palingan dicari, apa tujuan yang mau dicari. Di search gitu."

Informan lain juga nyatakan hal serupa, seperti akses rata-rata sekitar dua jam per hari. Ditambah lagi hampir semua informan juga menegaskan bahwa setiap harinya mereka mengkonsumsi Youtube jauh lebih banyak daripada televisi. Hal ini didukung dengan kemudahan yang mereka dapatkan dari perangkat ponsel pintar mereka. Artinya, di mana pun dan kapan pun mereka mau, aplikasi Youtube bisa mereka akses. Berbeda dengan sifat media televisi yang tidak bisa dibawabawa, meskipun perangkat televisi tersebut juga sudah berupa televisi pintar (smart tv).

Adapun konten yang diakses cukup beragam, yaitu berupa vlog, bahan ajar, musik, berita, kartun, konten komedi, hingga horror. Keberagaman konten dan kebebasan pilihan untuk mengakses konten yang disediakan oleh Youtube inilah yang membuat Youtube sangat digemari. Bahkan informan $\mathrm{V}$, YAF, menyatakan:

"Jika ada waktu lowong dan bisa memilih antara menonton youtube atau menonton televisi, saya akan menonton youtube. Meskipun saya tau tontonan youtube lebih beresiko karena tidak ada sensor dan aturan seperti televisi, tapi pilihan saya tetap pada youtube." 
Pengakuan informan tersebut sebenarnya juga senada dengan informan lainnya yang menyatakan bahwa mereka sadar bahwa konten-konten Youtube yang bersifat bebas itu cukup berbahaya, terutama bagi anak-anak dibawah umur. Tidak adanya regulasi yang membatasi pilihan atau mengatur kelayakan isi tayangan membuat Youtube lebih memberi candu pada khalayak pengguna. Tawaran akan kebebasan dari aturan dan rutinitas media televisi membuat Youtbe dinilai lebih fleksibel dan menarik.

\section{Penggunaan Youtube untuk mengakses Konten Non-Youtube}

Selain untuk mengakses konten-konten Youtube seperti vlog, para informan juga menyatakan bahwa mereka mengakses Youtube untuk mengakses konten non-youtube lain, seperti film dan tayangan program televisi. Ini menjadi menarik karena ini menunjukkan bahwa kehadiran Youtube selain memberi pilihan baru terhadap jenis konten atau program tayangan, juga memberikan kemudahan dan perpanjangan tangan dari media mainstream terutama televisi.

Beberapa hal yang dikemukan informan terkait alasan mereka "menonton televisi" dari Youtube adalah kemudahan waktu, artinya saat program televisi favorit mereka tidak bisa mereka tonton sesuai jam tayang, mereka bisa mengejar ketertinggalan tayangan dari channel yang mengupload episode tersebut, seperti yang dinyatakan oleh informan VI, NA "kalau ketinggalan episode rahasia ilahi, nontonnya di youtube". Hal ini sejalan juga dengan alasan lain yang dinyatakan informan V, YAF, yaitu:

"Di youtube kita bisa menonton bagian yang tunggu atau cari saja, tanpa harus menonton keseluruhan tayangan. bisa kita skip atau bisa kita pilih menit yang kita inginkan, misalkan tiga menit saja".

Meskipun juga ada hal yang menurut banyak informan yang menyatakan bahwa ada kelemahan youtube juga dibandingkan dengan televisi yang tidak begitu menyenangkan, seperti iklan. Iklan yang ditayangkan youtube terasa lebih mengganggu dibandingkan dengan iklan yang ada di televisi. Ini sebagaimana dinyatakan informan III, RR:

“iya, lebih mengganggu iklan youtube.

Karena iklannya tidak bisa di skip dan harus ditungguin. Kalau di TV kita bisa ganti saluran, di youtube harus ditungguin."

Selain iklan, masih ada beberapa faktor lain yang menjadi penentu dan menunjukkan berbagai kelebihan dan kekuranagn kedua media ini menurut informan.

\section{Penggunaan Televisi untuk menonton Program Stasiun Televisi}

Hal menarik ditemukan terkait pola khalayak menonton televisi. Hasil data penelitian menunjukkan bahwa banyak informan yang masih rutin menonton televisi, meskipun sudah ada media youtube yang menawarkan konten yang lebih beragam. Uniknya lagi, infoman yang menjadi penonton setia televisi ini, adalah dua infoman tertua dan termuda, yaitu informan I, NR (59 tahun), dan informan VI, NA (11 tahun).

NR menyatakan bahwa menonton televisi lebih menghibur daripada youtube, terlebih karena tidak perlu upaya lebih untuk menikmati program yang ditayangkan. Tidak perlu repot mencari dan menentukan apa yang perlu ditonton karena sudah terprogram dan terjadwal dari stasiun televisi yang bersangkutan. Penonton hanya tinggal menyalakan televisi dan menikmati. Bahkan hiburan yang didapatkan juga bisa menjadi selingan di sela aktivitas yang lain supaya tidak bosan saat melakukan pekerjaan.

Sementara NA termasuk banyak mengkonsumsi televisi karena aksesnya terhadap youtube masih terbatas. Meskipun NA mengaku lebih senang menonton televisi daripada youtube, durasi menontonnya 
televisinya hampir sama banyaknya. Ini dikarenakan NA belum mempunyai perangkat ponsel pintar sendiri. Jika ingin menonton youtube, NA harus meminjam gawai milih orang tuanya, dan itu juga tentu saja tidak bisa dengan sesuka hati. Bahkan dari pengakuan NA, terkadang dia mengakses youtube dengan diam-diam.

Sementara informan lain yang berusia dewasa awal hingga dewasa lanjut lebih jarang dalam menonton televisi. Kegiatan menonton televisi mereka lakukan sesekali saat berkumpul dengan keluarga atau di akhir pekan. Namun meskipun akses mereka pada tayangan televisi tidak terlalu banyak, informan II, ERR, menyatakan bahwa dia yakin bahwa televisi tidak akan mati atau tergantikan oleh youtube. Lebih lanjut beliau menyatakan:

"Kehadiran youtube menguntungkan televisi, karena dengan adanya media baru termasuk youtube, tivi bisa lebih cepat dapat mendapat informasi. Ada banyak juga konten youtube yang bisa diangkat dan dimunculkan di televisi. Tapi meskipun tidak akan hilang, yang pasti media tivi akan berubah".

Hal senada dinyatakan juga oleh informan IV, RR, yang menyatakan alas an lain yang membuat televisi akan tetap bertahan adalah adanya proses editing dan sensor yang membuat televisi lebih bisa dipercaya masyarakat. Menurut RR Youtube belum bias dipercaya sebagaimana televisi bekerja. Terlebih dengan akses yang terbatas, saat menonton televisi kita akan lebih sungkan untuk melakukan hal-hal yang tidak baik.

\section{Penggunaan Televisi untuk menonton Program Non-Stasiun Televisi}

Poin penggunaan televisi sebagai media menonton konten program non-stasiun TV ini hadir karena teknologi televisi pintar (smart tv) yang dimiliki oleh perangkat televisi saat ini. Ini merupakan suatu bentuk upaya televisi untuk bertahan dan tetap dikonsumsi meskipun terpaan media baru menawarkan beragam kemudahan.

Televisi pintar tidak lagi bisa kita samakan dengan televisi konvensional yang melihat definisi televisi sebagai sebuah kesatuan antara perangkat dan tayangan. Televisi pintar (smart tv) lebih cocok disebut sebagai perangkat karena akses dari perangkat tersebut tidak lagi terbatas pada program yang dibuat oleh stasiun televisi melainkan juga dari situs dan aplikasi lain.

Menariknya, ternyata meskipun televisi sudah berupaya melakukan transformasi tersebut, mayoritas informan yang memang telah memiliki televisi pintar (smart tv) di kediamannya masing-masing justru ternyata tidak mengaktifkan fasilitas tersebut. Mereka masih mempergunakan televisi tersebut secara konvensional, dalam artian tidak memanfaatkan fasilitas internet yang bisa disambungkan dengan perangkat televisi pintar ini.

Informan IV, RR, menyatakan mengakses internet dan youtube dari televisi membuatnya sungkan dengan anggota keluarga yang lain. Lebih nyaman baginya mengakses youtube melalui handphone saja. Sementara informan II, ERR, menyatakan meskipun televisi pintar bisa dipergunakan untuk mengakses internet, tombol pencarian dengan menggunakan remote yang harus menginput huruf demi huruf satu persatu sangat tidak praktis. Terlebih dengan menyambungkan televisi pintar dengan internet akan menambah biaya, seperti kuota.

\section{Pembahasan Hasil Penelitian}

Mediamorfosis sebagai evolusi teknologi dalam media komunikasi muncul sebagai tuntutan bentuk hubungan yang rumit akan kebutuhan media komunikasi. Kebutuhan masyarakat yang tinggi akan bentuk komunikasi yang lebih fleksibel, efektif dan efisien perlahan memunculkan inovasi pada media konvensional menjadi media baru. 
Media komunikasi yang hadir pada saat ini akan terus berkembang secara adaptif dan kompleks (Derwin et al., 2016). Media baru saat ini muncul dari metamorfosis media terdahulu. Media baru menjadi sebuah pilihan dalam menunjang eksistensi identitas pribadi individu di dalam masyarakat (Putri, 2012).

Konsep bahwa masyarakat memiliki motif dalam mengakses media menjadi latar belakang pemikiran bahwa media membutuhkan transformasi baik dalam bentuk perangkat maupun konten yang disuguhkan pada khalayak ramai. Adaptasi media konvensional menjadi media baru ini membentuk pemahaman kita bahwa sistem dalam media mengalami keterkaitan dan kesamaan dari masa lampau, sekarang dan menuju proses perkembangan di masa depan. Hal ini tentu saja menuntut adanya kreatifitas dalam industri siaran televisi konvensional.

Keberadaan youtube sebagai wadah dalam memunculkan konten-konten kreatif dilatarbelakangi dari kemunculan televisi dalam berbagai programnya, yang mana mewarisi sifat-sifat dominan televisi. Bentuk media yang ada saat ini merupakan hasil koevolusi dan konvergensi yang sering terjadi sepanjang waktu sehingga menghasilkan transformasi dalam penciptaan entitas baru.

Kebutuhan masyarakat dalam
membentuk pengalaman baru ikut bertransformasi pada bahasa. Bahasa dalam konsep mediamorfosis memberikan transformasi dalam bentuk pengalaman baru kepada khalayak atau penggunanya dalam bentuk teks dan pola konsumsi media. Komunikasi verbal digantikan dengan nonverbal dan kemudian menjadi bahasa digital. Contoh penggunaan Smart $T V$ yang tidak maksimal dan memilih youtube. Akses youtube lebih cepat, efektif dan efisien. Preferensi pribadi lebih diutamakan. Intensitas penggunaan media baru meningkat, setiap individu memiliki kesempatan menunjukkan preferensinya sesuai dengan kebutuhan. Setiap individu memiliki identitas pribadi di dunia maya. Individu juga mampu mengontrol konten-konten sendiri tanpa harus berbagi dan sepakat dengan kelompok dalam pemilihan program televisi yang disajikan.

Semua bentuk media komunikasi dan perusahaan media harus mampu beradaptasi dan berkembang dalam lingkungan yang sangat cepat berubah, karena teknologi tersebut tidak bisa langsung diadopsi oleh masyarakat. Media mengubah bentuk komunikasi dalam praktik sosial. Chaos sebagai komponen penting dalam perubahan media telah melahirkan entitas baru dan kemudian menghidupkan sistem (Achmad, 2020). Gagasan tentang adanya variasi kejadian dalam sistem yang terkesan tidak signifikan merupakan prinsip teori chaos. Tekanan eksternal dan penemuan baru inilah yang membentuk spontanitas bentuk komunikasi. Chaos akhirnya menciptakan media yang dinamis dan saling ketergantungan. Misalnya pada pengguna televisi dan youtube yng tidak bisa lepas satu sama lain. Di satu sisi, keharusan memiliki televisi merupakan sebuah kebutuhan akan pengakuan akan status sosial, dibarengi dengan berlangganan Smart $T V$. Namun di sisi lain, youtube pada gawai pribadi digunakan sebagai wadah untuk mendapatkan informasi dan hiburan dengan lebih cepat, ringkas dan privat.

Akhirnya pola baru terbentuk menjadi integrasi media atas organisasi dan produksi konten. Industri media memproduksi program acara untuk televisi, dan masyarakat juga tetap bisa mengakses program tersebut dalam youtube dalam bentuk konten kreatif. Youtube sebagai platform juga berlomba menyajikan konten yang kreatif dan inovatif mengikuti kebutuhan penggunanya. Mediamorfosis menyebabkan perubahan dalam komunikasi konvensional. Komunikasi yang terjalin pada interaksi dalam hubungan manusia secara biologis berganti dengan teknologi (Prabawanti, 2006). Interaksi biologis informan secara 
kelompok ketika menonton televisi menjadi berkurang, namun pemenuhan kebutuhan konsumi teks media secara individu meningkat.

\section{CONCLUSIONS}

Kesimpulan yang dihasilkan dari penelitian ini adalah perubahan fungsi pada youtube dan televisi adalah cara media menyesuaikan diri dengan kebutuhan konsumen. Sebagai konsumen media, mayoritas responden mementingkan konten daripada platform media yang mereka gunakan, sehingga media yang harus menyesuaikan diri dengan kebutuhan tersebut. Platform hanya berfungsi sebagai alat yang memudahkan mereka untuk mengakses konten yang mereka inginkan, tanpa mereka benar-benar peduli akan perbedaan konseptual dari pilihan media yang tersedia. Adanya transformasi fungsi pada media terutama televisi dan youtube adalah cara media beradaptasi dan mempertahanan diri. Sayangnya transformasi ini belum diiringi dengan kesiapan regulasi.

Adapun beberapa hal yang dapat disarankan dari penelitian ini antara lain:

1. Tidak terbatasnya konten yang disuguhkan oleh youtube mengharuskan pengawasan orang tua lebih ketat lagi terhadap aksesibilitas anak pada konten youtube.

2. Perlu adanya kebijakan atau regulasi yang mengatur konten-konten siaran yang disuguhkan oleh youtube.

3. Literasi media masyarakat sangat diperlukan agar masyarakat memiliki pengetahuan dan pemahaman dalam mencerna koneten-konten siaran baik yang tayang di platform televisi maupun platform youtube.

\section{ACKNOWLEDGEMENT}

Berlangsungnya penelitian ini adalah atas dukungan berbagai pihak, tanpa adanya peran dari pihak-pihak tersebut, maka penelitian ini tidak dapat berjalan. Ucapan terima kasih kami sampaikan kepada-pihak yang memiliki kontribusi dan turut berperan serta dalam penelitian ini.

\section{REFERENCES}

Abdullah, A., \& Puspitasari, L. (2018). Media Televisi di Era Internet. ProTVF, 2(1), 101-110.

http://jurnal.unpad.ac.id/protvf/article/vie wFile/19880/9080

Abraham, A. (2011). Sukses Menjadi Artis dengan Youtube. Reform Media PT. Java Pustaka Group.

Achmad, Z. A. (2020). Review Buku: Mediamorphosis: Understanding New Media by Roger Fidler. In Kriswibowo, A. \& Nawangsari E. R. (Eds.), Potret Masyarakat dan Kebijakan Pemerintah dalam menghadapi tantangan Pandemi Covid-19. https://doi.org/10.31947/etnosia.v3i1.4155

Akbar, A. (2018). Efektifitas Youtube Sebagai Media Penyebaran Informasi [Universitas Islam Negeri Ar-Raniry]. https://repository.arraniry.ac.id/id/eprint/5845/4/Ali Akbar.pdf

Cangara, H. (2011). Pengantar Ilmu Komunikasi. PT Raja Grafindo.

Derwin, D., Suharto, S., \& Syamsuri, S. (2016). Aksesibilitas Media Sosial Dakwah Mahasiswa Komunikasi Penyiaran islam (KPI) IAIN Palu. Al-Mishbah, 12(2), 183210.

http://download.garuda.ristekdikti.go.id/ar ticle.php? article $=1296968 \& \mathrm{val}=17452 \& \mathrm{ti}$ tle=AKSESIBILITAS MEDIA SOSIAL DAKWAH MAHASISWA KOMUNIKASI PENYIARAN ISLAM KPI IAIN PALU

Effendy, O. U. (2005). Ilmu Komunikasi Teori dan Praktek. PT. Remaja Rosda Karya.

Fajri, C. (2015). Fungsi Rajawali Citra Televisi Indonesia (RCTI) dalam Membentuk Ruang Publik. CHANNEL Jurnal Komunikasi, 3(1), 15-22. https://doi.org/10.12928/channel.v3i1.241 6

Fidler, R. (2003). Mediamorfosis: Memahami Media Baru. Bentang Budaya.

Flew, T. (2008). New Media: An Introduction (3rd Edition). Oxford University Press. 
Gusnita, C., \& Alviani, S. R. (2018). Analisis Media Sosial Sebagai Pembentuk Konflik Sosial di Masyarakat. Open Society Conference 2018: Social and Political Challenges in Industrial 4.0, 221-241. http://repository.ut.ac.id/7962/1/ocs-201812.pdf

Hanana, A., \& Elian, N. (2017). Perilaku Konsumsi Media Maya (Cyber Media) Pada Anak Di Kota Padang. Prosiding Celscitech, 2, 60-65. https://core.ac.uk/download/pdf/32721766 6.pdf

Handayani, F. P., \& Merdekawati, I. (2019). Kebijakan Penggunaan Media Online Website Kompas TV Dan Youtube Untuk Menyalurkan Konten "Eksklusif Digital" Kompas TV. Jurnal Kajian Jurnalisme, $3(1)$, 198-211. https://doi.org/10.24198/kj.v3i1.21361

Kuswandi, W. (2008). Komunikasi Massa: Analisis Interaktif Budaya Massa. Rineka Cipta.

Mangole, K. D. B., Himpong, M., \& Kalesaran, E. R. (2017). Pemanfaatan Youtube Dalam Meningkatkan Pengetahuan Masyarakat Di Desa Paslaten Kecamatan Remboken Minahasa. Jurnal Acta Diurna, 6(4), 1-15.

Mcquail, D. (2000). Mass Communication Theory. Sage.

Morissan. (2008). Manajemen Media Penyiaran. Kencana.

Prabawanti, B. E. (2006). Peran Komunikasi Sebagai Pendukung Perubahan Organisasi. Bina Ekonomi, 12(1), 78-86. https://media.neliti.com/media/publication s/12819-ID-peran-komunikasi-sebagaipendukung-perubahan-organisasi.pdf

Putri, D. U. (2012). Peran Media baru dalam Membentuk Gerakan Sosial (Studi Kasus pada Individu Yang Terlibat dalam IndonesiaUnite Di Twitter) [Universitas Indonesia].

http://lib.ui.ac.id/file?file=digital/2028966 1-S-Dibyareswari Utami Putri.pdf

Rakhmat, J. (2008). Psikologi Komunikasi. PT Remaja Rosdakarya.

Sulvinajayanti. (2018). Manajemen dan Konvergensi Media Penyiaran. Penerbit Aksara http://repository.stainparepare.ac.id/839/1/ Manajemen dan Konvergensi Media Penyiaran.pdf

Vivian, J. (2008). Teori Komunikasi Massa. Kencana.

Wijaya, S. (2010, March 14). Media Cetak Bersaing dengan Internet. Produser BBC Indonesia. https://www.bbc.com/indonesia/laporan_k husus/2010/03/100312_mediainternet

Yulianti, S. (2013). Persepsi Masyarakat Tentang Program Acara Reality Show "Catatan Si Olga" di Kelurahan Gunung Lingai Kecamatan Sungai Pinang Samarinda. EJournal Lmu Komunikasi, 1(1), 46-61. https://ejournal.ilkom.fisipunmul.ac.id/site/wpcontent/uploads/2013/02/01 format_artike 1_ejournal_mulai_hlm_ganjil (02-27-1312-50-12).pdf 